Seventh Meeting, June 12th, 1896.

Dr Peddie, President, in the Chair.

\title{
Vorlesungen über Geschichte der Mathematik, von Moritz Cantor. Dritter Band.
}

Erste Abtheilung 1668--1699 (1894).

Zweite Abtheilung 1700--1728 (1896).

A Review : with special reference to the Rise of the Infinitesimal Calculus and the Newton-Leibnitz Controversy.

By Professor George A. Gibson.

The gigantic task which $\mathrm{Mr}$ Cantor has undertaken in writing a history of mathematics down to the year 1759 is approaching its accomplishment, the first two of the three parts forming the third and concluding volume being now published. How great is the debt of gratitude that the mathematical public owe to him for the erudition and thoroughness he has brought to bear on the work, only those can guess who have attempted to follow out some line of historical investigation. His history is totally different from a catalogue of authors and their works; it enables us to trace clearly the lines of deveiopment of mathematical knowledge and shows with wonderful skill not only the contributions made by the creators of the science but the conditions and materials that made these possible. The fact that the greatest mathematicians recognise that they obtained their position becuuse "they stood on the shoulders of great men" does not in the least detract from their merits but is an abiding augury for future developments.

The closing portions of the second volume of $\mathrm{Mr}$ Cantor's History are full of preparations for the evolution traced in the third volume of the facts and the algorithm of the Infinitesimal Calculus, and these preparations themselves rest on the work of the great mathematicians of antiquity. The third volume is of special interest because there we have the explicit development of the analysis that bulks so largely in modern mathematics. A detaile. 
examination of the various chapters in these two parts would demand more space than our Proceedings can afford, even if I were competent to make it, and I propose therefore to deal mainly with the rise of the Differential and Integral Calculus and the controversy between Newton and Leibnitz in regard to the invention. It would seem as if every document of importance, so far as these are ever likely to be found, were now before the world ; and the judgment of the mathematical public respecting the controversy might be expected to be formed in as definite a way as the nature of the dispute admits.

It is now, I think, generally recognised and in any case it is emphasised by $\mathrm{Mr}$ Cantor that the second half of the seventeenth century was ready for the instrument that we denote by the Infinitesimal Calculus and that the writings of men like Cavalieri, Fermat, Pascal, Wallis contain many processes and results that would now be classed as characteristic of that Calculus. The question therefore that naturally arises is, what was the gain to mathematics from the work of Newton and Leibnitz in the field of the infinitesimal calculus? As regards the controversy between the two, there is the further question, did the one derive from the other ideas, suggestions, or results that were of importance for the development of his system?

In the closing paragraphs of his second volume $\mathrm{Mr}$ Cantor has stated that the half century from 1615 to 1668 may be considered to be that of the discovery of the Infinitesimal Calculus; first, problems of the Integral Calculus were treated, next problems of the Differential Calculus, then problems in which both appeared, but the intrinsic connection between the two branches was only dimly perceived. The task that devolved upon the mathematicians who succeeded these pioneers was to make explicit this connection and to provide an instrument of research in the shape of an appropriate notation and algorithm. On p. 125 of Vol. III. Mr Cantor repeats this summary, and lays stress on the discovery of a notation as the condition for further advance, while apparently considering as of less importance the appreciation of the relation between the two branches. At any rate, throughout the analysis and discussion of the writings of Newton and Leibnitz it is the presence or absence of a notation and an algorithm, "of a grammar of the language" that he most frequently insists upon. 
The predecessors of Newton and Leilmit\% had given many examples of infinitesimal operations; those of the differential calculus appeared for example in the drawing of tangents, and in the investigation of maxima and minima; those* of the integral calculus in quadratures, \&c.; while the inverse method of tangents was closely related to differential equations. In the beginning of our study of the Calculus now-a-diays we learn first the simpler operations of differentiation and we usually (unfortunately) advance pretty far in the differential calculus before broaching the integral; but when we do come to integration we treat it as the inverse of differentiation. Now this inverse character of differentiation and integration had to be seen before there could be much of an integral calculus; in other words, only thus could the essential identity of problems in the direct and inverse method of tangents and in quadratures be perceived. I fully agree with Mr Zeuthen (Bulletin de l'Acad. Roy. de Danemark, 1895, No. 2) that the recognition of this inverse character is a fundamental condition for the rise of the Calculus, as a system; and $\mathrm{Mr}$ Cantor, while not forgetful of it, has perhaps laid too much stress on the invention of notations and algorithms.

Again in the development of a calculus that was to go much beyond the earlier results there was one essential instrument, viz., the binomial theorem for any index. Without this theorem and the explicit use of fractional and negative indices the algorithm of the new calculus would have been very imperfect and advance very slow.

For the rise of the new calculus then, there is needed the recognition of the inner connection of the various methods of solution of such classes of problems as those noted, and for its development there is necessary a notation and an algorithm. But there is also needed an algebraical improvement - the binomial theorem, and the binomial theorem suggests infinite series. There seems little doubt that when the calculus took shape and for long after, the theory of series was held to be a distinct subject; Newton himself in a wellknown letter to Keill (Edlestone's Correspondence, pp. 170-3) expressly makes the distinction. Yet but for series Newton's contributions to the new method would have been very different from what they were. His work in the field of series has been as epochmaking as in other fields, and one may fairly consider the method 
of series as forming for Newton an indispensable adjunct to his calculus. Integrations in tinite form are important, but without infinite series the structure of the Calculus, whether viewed theoretically or practically, would be stripped of some of its most valuable features. In considering then the contributions of Newton and Leibnitz to the development of the Calculus we must look not merely at the formal side-the construction of a notation and algorithm, but also at the material-the discovery of the results that make it valuable.

$\mathrm{Mr}$ Cantor in view of the miserable controversy about the invention of the Calculus and the influence on it of the personal circumstances of the two great rivals narrates the story of their life in unusual detail.* In this country we are perhaps more familiar with the personal characteristics of Newton than with those of Leibnitz. $\dagger$ As regards the latter, it is perhaps too often forgotten that the study of mathematics was not the principal pursuit of his life and that at what may be called critical periods he was often overwhelmed with duties of a totally different kind. Nor did he owe much of his mathematical skill to his University training; the account of one of his teachers, Erhard Weigel (pp. 36-7) is a startling revelation of the state of mathenatical instruction in the German Universities of the period. As Jeibnitz himself says, he was when he came to Paris in 1672 self-taught in mathematics and had only a superficial acquaintance with the higher branches. His introduction in 1673 to Huygens was the turning-point in his mathematical career and he always gratefully recognised how much he owed him for direction and stimulus. I feel obliged to add that I think Leibnitz possessed in a pretty high degree faults that are too often inherent in the self-made man; his self-consciousness is excessive and the self-satisfied tone in which he speaks of his achievements, though at times amusing, is frequently offensive. In this respect he presents a striking contrast to Newton.

The writings of Newton that are of most importance for our purposes are (1) De Analysi per aequationes numero terminorum infinitas, sent to Collins in 1669 but first published in 1711 ; (2) De Quadratura curcarum, published in 1704 ; (3) Methodus

* The statement on p. 65 that the binomial theorem was cngraved on Newton's tombstone seems to be a mistake.

$\dagger$ According to Mr Cantor we should write Leihniz. 
Fluxionum et Serierum infinitarum, published in 1736. Besides these are three letters, one to Collins in 1672 that may be called "the tangent letter" and two to Oldenburg (to be communicated to Leibnitz) the first dated 13th June 1676 and the second 24th October of the same year. (1) was printed in 1711 in the form in which it was sent to Collins but it was probably drawn up in 1665-6. Whether (2) and (3) underwent revision before publication can not be definitely decided, but it seems certain that the substance of (2) dates back to about 1666 and in any case not later than to 1676 while (3) was probably written, nearly as we have it, in 1671 . The reasons urged on p. 165 in favour of a revision of (3) are not, I think, well founded (see Mr Zeuthen l.c.), though Mr Cantor is on stronger ground when he argues (p. 171) for an addition later than 1673.

To what extent Collins made known the contents of the $D e$ Analysi, it seems difficult to determine; the letters from Collins printed in the Commercium Epistolicum contain several of the series and intimate that Newton has a general method, applicable to quadratures, rectifications, drawings of tangents, \&c., but they give no clue to what that method is. James Gregory in replying (15th February 1671) to one of Collins's letters says he thinks he knows Newton's general method to some extent and communicates certain series of his own, among them that for $\tan ^{-1} x$; Collins (21st February 1671) writes that Gregory " has very recently fallen upon the same method" (as Newton's) - a mode of expression that seems to imply that he had told Gregory nothing of Newton's procedure. However this may be, 1669 may be considered, in discussing claims for priority, as the year of publication of the De Analysi.

I cannot here enter with any detail into the writings named above ; I can only indicate results that are of special importance for the development of the Calculus. First, I take the De Analysi. There we have the following :-

A. $x, y, z$ denoting the abscissa, the ordinate and the area of a curve, the rule for obtaining $y$ when $z=\frac{n}{m+n} \times a x^{\frac{m+n}{n}}$ is proved, and conversely the value of $z$ is noted when $y=a x^{\frac{m}{n}}$. In the examples the index has negative as well as positive values, and a special set illustrates the meaning of the negative coefficient; $x^{-1}$ is 
also considered. * Newton further remarks that, by assuming any equation whatever between $z$ and $x, y$ may be found in the same way ; e.g., if $z=\sqrt{ }\left(a^{2}+x^{2}\right)$, then $y=\frac{x}{\sqrt{a^{2}+x^{2}}}$.

B. If the expression for $y$ is not a simple sum of powers of $x$, it is expanded in series and to each term the general rule is applied. To obtain the series, the binomial theorem (or rather divisions and root extractions) is applied if $y$ is an explicit function of $x$; but when $y$ is an implicit function it is expanded, in ascending or descending powers of $x$, in the now well-known manner, and the question of convergence of series is not passed over.

C. Newton's principle of "moments" is stated and applied to finding the length of a circular arc; this section seems to me to be one that the first readers of the tract would find very difficult.

D. The number and the importance of the series obtained are very striking; besides the binomial theorem, there are the series for $\sin x, \cos x, \sin ^{-1} x, e^{x}, \log (1+x)$, in fact all the important elementary series. The expansion of $y$ when given as an implicit function of $x$ and the reversion of series are very important methods which are sketched in a most instructive manner.

In the tract the general method of measuring " the quantity of curves" is professedly "briefly explained rather than accurately demonstrated," but the closing sections return to the proofs. It would be too much to say that they meet modern demands, but they are the work of one thoroughly imbued with the spirit of accuracy characteristic of the ancient geometers.

It seems to me beyond all question that Newton has here made a new departure; the relation, as we would say, of integration to differentiation is clearly expressed and the method is general because it embraces problems which were formerly solved each by its own special method. It is, as Mr Cantor says, quite true that there is no trace of the differentiation of products and quotients, nor is there any special notation; but there is a working system such as had not yet appeared, shedding a new light on the old problems and capable of results of the most important kind. In fact, what we understand by the "Calculus" has now been discovered, and the whole

"Mr Cantor's phrase (p. 151) "perhaps also negative" is not justifiable. 
style of the arrangement and composition proves that Newton has only given a sample of the stores in his possession.

Next I should say something of the other two treatises, but as regards the relation of Newton to Ieibnitz these do not occupy the same position as the first one. It is important however to notice that they completely bear out all the claims Newton puts forward in the tangent letter and in the letters to Oldenburg. The $D e$ Quadratura is as much a treatise on integration as on what we call quadrature, and is a very thorough piece of work, containing as it does standard forms and groups of integrals which prove how fully Newton had realised the importance of his method and the necessity of having the standard results at command. I think $\mathrm{Mr}$ Cantor has dwelt too much on the slips Newton occasionally made; they bulk too largely in the History. Mr Cantor's admiration for New. ton's work is sincere and I can hardly think he is quite aware of the impression his frequent reference to the slip (for $I$ thirk it is a slip) regardirg the relation of fluxions and increments will leave on readers of his book. Again his criticism (p. 165) of Newton's procedure in making the fluxional equation homogeneous seems to me unreasonable, nor I think does Mr Zeuthen quite meet the objections. It seems to me from Newton's repeated observations in the Methodus fluxionum, that a fluxional equation is for him simply meaningless unless it is homogeneous in the fluxions, exactly as Leibnitz argues for homogeneity in differentials. There is an apparent arbitrariness in introducing a new fluxion, but the real meaning of the process seems to me quite clear. For a most valuable statenient of Newton's work from a somewhat different standpoint from that of $\mathrm{Mr}_{\mathbf{r}}$ Cantor I would refer to Mr Zeuthen's articles mentioned above. *

The tangent letter (10th December 1672) was apparently sent to Collins, who had heard of Sluse's method, in reply to an inquiry as to what Newton could do in that field. Newton says he thinks he knows what Sluse's method must be and states a rule, illustrating it by an example, which is effective when the equation of the curve is rational and integral. His rule is in substance the same as Sluse's (showing how to construct the subtangent) and is given almost in the same words as he uses for the rule for finding the

* When Newton makes the sulstitutions 1-x, c-ä for $x$ (Opuse. I. 69) he omits to change the sign of $x$; but see Opuse. I., ly. S4-j. 
fluxion of an expression in the Iethodus Fluxionum (Opuscula I., p. 55). In both cases he speaks of "any arithmetical progression whatever"; the meaning of this phrase is not quite clear (but see Op. I., 61), though the correct progression is used in the example. The peculiar phrase noted, though making the rule less clear and even inaceurate for the particular example, may have been used in view of the rest of the letter in which Newton says that the rule is a mere corollary of a general method, and is, unlike Hudde's method for maxima and minina, applicable even when the equation contains surds, while extencling also to more difficult problems in curvature, areas, \&c. From this letter $I$ do not think any one could learn more of the method of tangents than he might from Sluse or Hudde; there is only this other information that Newton claimed to be able to do more than these two. It is a bold statement that " in this letter the method of Fluxions was sufficiently described to any intelligent person."

Reading the two letters to Oldenburg and the tangent letter in the light cast on them by the De Qundratura and the Methodus Fluxionum one can hardly doubt that by 1676 Newton was in possession of his new analytical methods almost as he left them. With him notation and algorithm are of very secondairy importance, and it was only after much fluctuation that he adopted the notation he actually published; the superiority of the Leibnitzian calculus in this respect, though denied by Newton and his immediate successors, must be held as proved by the subsequent development of the higher mathematics. On the other hand that development owed much to Newton's work in the field of infinite series where he was an acknowledged master, Leibnitz himself always admitting Newton's merits here even when embittered by the priority controversy. It is not easy to determine how far Newton himself distinguished between the method of fluxions and the method of infinite series, and it was always a sore point with Leibnitz that the English adherents of Newton turned the priority dispute on matters of series in which he granted Newton's priority and pre-eminence. In their own day and for long after, a distinction was recognised, though infinite series formed an important element in many applicacations of the calculus and were really essential to its progress. The restriction of the calculus to operations which were effected on, or resulted in, expressions in finite form is very arbitrary; but that 
some such restriction was made is implied in the manner in which writers of that time spoke of the subject. Newton, however, after laying down in clear terms the fundamental principle of the formation of fluxions and of returning in the simpler cases from the fluxions to the fluents proceeds to apply that principle by a systematic use of infinite series, but is also on the watch for closed expressions as particular cases. The integration, as we would now say, of the binomial differential (stated in the 2nd letter to Oldenburg and proved in the De Quadratura) is a remarkable instance.

Whether Newton fully realised the importance of his work on fluxions and series before the brilliant results of Leibnitz and the two Bernoullis showed the importance of the method, can not be definitely settled; that he valued it highly is clear from the letters to Collins and Oldenburg, but it would almost seem as if the enormous labour he bestowed on series had produced a sort of reaction. This feeling comes out in the two letters to Oldenburg and still more strongly in his communications with Wallis, where he spoke of himself, Wallis says, as harum rerum pertaesus, leaving to others who might have the leisure and the will an open field in which to exercise themselves. (Letter to Leibnitz, January 16th, 1699.) His aversion to controversy prevented him from publishing an account of his methods, as he had intended to do, in 1671; but no one, I suppose, will question that his method of fluxions is essentially the same as the differential method of Leibnitz and that he was in possession of it several years before him.

In going on now to speak of Leibnitz, I recognise the extreme difficulty of deciding how much he may have derived from the writings of Newton that he is known to have seen, and that will be mentioned at the proper place. Suggestions that are obvious to us who have been trained in the calculus may simply have been hidden completely from a reader of Newton who was quite new to the subject; and it is always a risky proceeding to impeach a man's honesty on the grounds of suggestion. Many of the foot-notes in the Commercium Epistolicum carry this procedure to a most unjustifiable extent and reflect as little credit on the judgment as on the fairness of the editors of that book.

Up till 1672 Leibnitz had done very little in mathematies, but it is, I believe, generally admitted that from the very first he recognised the value of form. Notations and algorithms held a 
prominent place in his conceptions and, as he wrote at a later date (1693), only repeating a remark found in a manuscript dated 20th March 1676, "one part of the secret of analysis consists in the characteristic, that is to say in the art of employing well the symbols we use." His earliest work was in the theory of combinations and a little later he is found working at numerical series. Early in 1673 he visited London but did not on this occasion, it would seem, make the acquaintance of Collins. When in London he met the mathematician Pell and in the course of conversation mentioned a method he had of treating series, which he called the method of "generating differences"; but Pell pointed out that it was already known. On getting the book by Mouton which Pell referred to, Leibnitz found the correctness of Pell's statement. In order however to clear himself from any possible charge of plagiarism he addressed a formal letter to Oldenburg explaining how he had come upon his own method and pointing out that he went further than Mouton. This incident was afterwards adduced in proof of Leibnitz's plagiarising propensities, though I hardly think with reason. At a later period Leibnitz always declared that his studies in the method of generating differences gave him a clue to his differential method.

In London he got Mercator's Logarithmotechnia (published in 1668 ) and the study of this work and of other works recommended to him by Huygens led him to what he calls a general method of transformation by means of which any given figure is "transmuted" into an equivalent one involving an equation of no higher degree at most than the third. I cannot say I think he has proved what he claims for this method of "transmutation" (as be calls it) but at any rate it enabled him to find series for the areas of sectors of central conics. One of these series is the same as Gregory's series, and here again a charge of plagiarism has been made. But Leibnitz's mode of proof is that of Mercator rather than that of Newton and a letter of Huygens shows that Leibnitz sent him the series (for $\pi / 4$ ) before he had any means, so far as we know, of seeing Gregory's series. Such coincidences are very unfortunate for Leibnitz in view of the later dispute, but Mr. Cantor's cliscussion proves, it seems to me, Leibnitz's honesty in the two cases.

The most important part of Leibnitz's mathematical studies during his residence in Paris from 1673 to 1676 consists in his 11 Vol. 14 
researches on the borderlands of the calculus. Since the most convincing proofs of Leibnitz's independence are the contents of his notebooks of this period, it is a painful but a necessary duty to state that a falsification of date has been detected in one of his MSS., 1675 being altered to 1673 . Mr Cantor, with his usual fairness, mentions this (p. 176) and assumes that it is the act of Leibnitz himself. At the same time I think the conclusions he draws are sound;-(1) that the detection of one falsification would induce a careful scrutiny of the other dates and as no further tampering has been noticed we may conclude that the other dates are genuine; and (2) that the date of 1675 is definitely established.

Assuming then the genuineness of these MSS., I think we may hold it as proved that before he had any information regarding Newton's methods and before his second visit to London in 1676 Leibnitz was already on the tracks of his general methud. It may be noted in passing that the procedure of the earlier analysts for drawing a tangent lay in tinding the subtangent. The right-angled triangle formed by an intinitesimal arc and the differences of the abscissae and of the ordinates of the ends of the arc is called by Leibnitz "the characteristic triangle" and is fundamental with him; it is obviously similar to the triangle formed by tangent, subtangent and ordinate. Whether he got the idea of this triangle from his study of Pascal (as he always maintained) or from Barrow, does not much matter-except as another instance of his duplicity; $\mathrm{Mr}$ Cantor makes out a very strong case for the correctness of Leibnitz's assertions.

From the MSS. then we may conclude

A. That he is in possession of his symbols $d$ and $\int$ and recognises their inverse character ; he knows the difference between $d x d y$, and $d(x y)$ and between $d x / d y$ and $d(x / y)$, and believes they will furnish a new kind of calculus. He further sees

B. That the inverse method of tangents is reduceable to quadratures; he even solves a simple problem.

C. "That the true general method of tangents is by differences; namely the difference of the ordinates (direct or converging) must be sought for. Whence it follows that even quantities not otherwise subject to calculation may be subjected to the calculus of 
tangents provided their differences are known" (MS. of date 26th June 1676). In a MS. of the following July the solution of De Beaune's problem is found.

It seems to me characteristic of these MSS. that the results are usuably got by beginning with known problems, solved or unsolved.

Leibnitz then may fairly be said to have laid the foundations of his calculus; I do not think however he had gone very far in the actual development of it. Further, I do not think that anything in the MSS. referred to above could be due directly to any communications from Oldenburg or Tschirnhaus; I accept Mr Cantor's conclusions on this point.

We now come to Newton's first letter, sent off by Oldenburg on 26th July 1676. Along with this was sent a resumé of the tangent letter which did not contain the example but stated Newton's claims for his general method, in particular that it did not stick at surds. Newton's first letter contained the binomial theorem and the statement of the use of fractional and negative indices; the method of expanding implicit functions ; several of the series of the De Analysi: and several examples of quadratures and rectifications by series.

I do not think Mr Cantor has given due weight to the help this letter might have given to Leibnitz; so far as $I$ can judge his algorithm made little progress till he became familiar with the binomial theorem and was sure of his fractional and negative indices. His efforts to secure expressions in finite form, which $\mathrm{Mr}$ Cantor thinks characteristic of Leibnitz, could have but little success without such instruments. And further, Leibnitz's characteristic of working from given problems was provided with a splendid field to exercise in.

To this letter Leibnitz replies on the 27 th of August. He first explains his method of transmutation-not a lucid exposition by any means. He then proceeds to give series which occur in Newton's letter and seems to claim that he had found them for himself. 'Towards the end he mentions that he has lately solved De Beaune's problem-which passed the skill of Descartes but which he had solved within an hour by the help of a certain analysis. He adds however that in this field he has not yet effected much, though he knows it to be of the greatest moment.

In the letter his symbols do not carry their signs with them, and indeed for several years he did not grasp the generality of 
method which Newton in his reply shows him is to be gained by letting the symbols include the signs. But what are we to say about the series which he seems to claim as having also been discovered by himself and of which he gives no proof? If he did discover them for himself, I cannot but think he was enabled to do it by means of the theorems Newton had given (without proof, as Mr Cantor insists) in the letter to which Leibnitz was replying. If he did thus discover them, he gives a strong proof of his ability to profit by comparatively obscure suggestions and at the same time discloses an unfavourable feature of his character in not saying that such was the origin of them. As Newton referred to this matter in his next letter, in somewhat reproachful terms, it was incumbent on Leibnitz to put him right on his method of procedure.

However that point may be settled, Newton was evidently greatly pleased with Leibnitz's communication and drew up, under date 24th October 1676, a very long letter in reply, but when the reply reached Leibnitz has been subject of dispute. In the end of October he was in London for about a week and it is probable that on this visit he saw at Collins's the MS. of the De Anclysi and made those extracts from it that are now among his documents in the Royal I Library at Hanover. That he should have seen at Collins's a letter addressed to himself, under cover to Oldenburg, and not have taken possession of it seems quite incredible and until there is evidence to the contrary I think we must assume that he got his first acquaintance with it from the copy which he received on 21st June 1677; the letter was certainly in London on 5th March 1677 , as we learn from a letter from Collins to Newton.

Leibnitz had put several questions, and Newton answers them very fully; but he sends him a great deal more. He refers to his general method but cleclines to reveal it, consigning to two anagrams its leading principles. He evidently wished to retain his rights in his discovery and I fancy he thought he had both secured his rights and also kept his method a secret. My chief wonder is that he sent so many of his results as he did, for the letter is indeed a very remarkable document and contains a synopsis of the De Quadratura that only Newton himself could have drawn up. Of direct demonstration there is little ; and though, as I think, it was of no immediate use to Leibnitz, it may have stood him in great stead for his later work. Whatever future ase he may have made of it, he proceeded 
to reply on the day he received it. Unfortunately the word hodie on Leibnitz's own draft (a genuine hodie, not of later insertion) was omitted, through some unexplained cause, on the copy that was current in England, and $\mathrm{Mr}$ Cantor dwells at great length on the probable effects of the omission.

In his answer Leibnitz makes his first open use of his differential notation and shows by examples that he is in possession of a method of tangents that does not stick at surds. The actual calculations are however affected with blunders in differentiating the surds that can hardly be set down as slips of the pen, though the preliminary explanations of obtaining tangents by differences are quite clear; the underlying principle was indeed quite common property by this time and the really new application was to surd quantities. Newton had claimed that he had surds in his power and Leibnitz wanted to show that he also had a method that did not stick at surds. Mr Zeuthen has an ingenious theory that Leibnitz owed his solution to a generalisation of the solitary example that occurs in the De Analysi, namely that if $z=\sqrt{ }\left(a^{2}+x^{2}\right), y=\frac{x}{\sqrt{\left(a^{2}+x^{2}\right)}}$. If this be correct, then Leibnitz had a marvellous power of profiting by suggestions, but I hardly think that this theory is sufficient. It is perfectly clear in any case that Leibnitz had very little command over fractional indices; he still used the old notation for roots of quantities; and there can be little doubt, as Mr Cantor supposes, that he thought $d(\sqrt[n]{x})=d x / n(\sqrt[n]{x})$ without seeing that this contradicts the rule he had previously given, namely, $d\left(x^{2}\right)=z x^{2-1} d x$. But the mistakes in differentiating, which must soon have been discovered and actually were so, hardly affect the principle of the method, which is that the differential $d x$ must come outside the root. Now Leibnitz himself in a letter to de l'Hospital (of a much later date, it is true, 27 th December 1694) expressly says in explaining the origin of his calculus, that "he saw that the differential quantities would necessarily come outside the fraction or vinculum "; and comparing this statement with $\mathrm{C}$ (above) $\mathrm{I}$ am disposed to believe that he had guessed, even before seeing the De Analysi, that his method would extend to surds. He had, as I believe, worked, up till this period, very little with the more complex surd expressions; but he may well have reached the fundamental principle, either by substitution as in the letter, or by direct use of the binomial theorem. It 
is perhaps worth noting that Keill, in his letter to Sloane, insists on the help Leibnitz got from the binomial theorem for the extension of his results beyond those of Sluse and uses the same expression as is found in the letter to de l'Hospital, namely, "where we see that the differential quantity $\frac{m}{n} c b x^{c-1} d x$ always remains outside the vinculum"; I fancy it was this property that first struck Newton himself.

Leibnitz does not refer in this correspondence to his having seen the $D e$ Analysi when in London, and $\mathrm{Mr}$ Cantor very justly censures his silence, while trying at the same time to explain it. His continued silence cannot but rouse suspicion and though his future frequent appeals to Newton to publish his general method induce one to believe that he was not conscious of making any unfair use of the lights he had obtained from Newton, it is not altogether unreasonable that suspicions should so long have been entertained of him.

Newton sent no reply to this letter of Leibnitz, and henceforward they work apart. Up to this point Leibnitz has shown great capacity and has, I think, given ample proof that the seeds of his new calculus are germinating in his mind and that he has, independently of Newton, got upon the right track. But he is a mere tyro as compared with Newton, and has given very little of actual mathematical results for the rich fund that Newton supplied. How the new calculus would have shaped itself had the correspondence continued, it is impossible to say; but Leibnitz soon showed the best qualities of his genius by working out the algorithm of his method and applying it to all sorts of mathematical problems. However much he may have owed to the contents of Newton's letters or MSS. -and that point can never be settled definitely-he was certainly the first to introduce the mathematical world to a calculus that has borne the richest fruits.

In the Acta Eruditorum for 1684 Leibnitz gives the first public exposition of his calculus, being probably forced to take this step by the fear that Tschirnhaus would steal a march upon him, though a MS. of 11 th July 1677 seems to indicate that even at this date he had thoughts of publication. The title of his paper is Nova methodus pro maximis et minimis, itemque tangentibus, quae nec fractas nec irrationales quantitates moratur et singulare pro illis 
calculi genus. The differential $d x$ is not defined as an infinitesimal, but is arbitrary and such that $d y / d x$ expresses the ratio of the ordinate of a curve to the subtangent. Rules are stated but not proved for the differentiation of constants, sums, products, quotients, powers, roots; he uses substitutions for complex expressions; and he mentions a test for maxima and minima. It is clear that the paper excited considerable attention, as in a work * published at London in 1685 by John Craig, a Scotchman resident at Cambridge, the method of Leibnitz is approvingly referred to and used. In 1686 Leibnitz has another paper in the Acta, entitled De geometria recondita et analysi indivisibilium atque infuitorum, and here the integral sign appears for the first time in print. It is perhaps worth noticing that he gives the equation $y=\sqrt{ }\left(2 x-x^{2}\right)+\int \frac{d x}{\sqrt{\left(2 x-x^{2}\right)}}$ which occurs in the De Analysi, and adds " this equation perfectly expresses the relation between the ordinate $y$ and the abscissa $x$, and from it all the properties of the cycloid may be proved; and in this way the analytical calculus is carried forward to those lines which have hitherto been excluded for no other reason than that they were believed unsuited for it." It is not unfair to conclude that he may have been indebted in the same way to other results of Newton for the illustration of his calculus; not that there is anything to complain of in this, but it does show that he is not so independent of Newton as he seems to make out.

He also introduces in this article his distinction between transcendent and algebraical quantities and points out that his calculus is also applicable to the former, the equation just cited being an illustration.

A historical summary that Leibnitz gives is noteworthy because of the language of hearty commendation in which he speaks of Newton and of what Newton has "excogitated"; he believes that if Newton would only publish what he has by him he would without doubt open up new avenues to the great advance of science.

In 1687 appeared the Principia. That Newton made no explicit use of fluxions in this work is, to my mind, sufficiently explained by the reasons usually advanced; but of more importance for present

* In this work, Mcthodus figuramu . . . quadraturas cleterminandi, the binomial theorem appeared in print for the first time. 
purposes is the celebrated scholium in which Newton states that in letters which passed between him and Leibnitz ten years before, he had mentioned that he was in possession of a general method for tangents, \&c., which did not stick at surds but had concealed it under an anagram, and that Leibnitz in reply had said he too had fallen upon a method of that kind and communicated it, the method of Leibnitz hardly differing from his own except in the form of words and notations. The plain meaning of this declaration in my opinion is, that at the time of writing the Principia Newton believed he had concealed the principle of his method by means of the anagram, and that Leibnitz had hit upon his in some other way. In the second edition of the Principia (1713) another difference in the methods is noted, namely, "the idea of the generation of quantities"; whether this addition was due to Cotes or Newton can not be decided ; its importance can not be questioned. But in the third edition (1726), when Leibnitz was dead and the dispute for the time dying away, the scholium was completely altered; Leibnitz's name was omitted and the tangent letter to Collins took the place of the former correspondence.

Mr Cantor considers the scholium of the first two editions as admission by Newton of Leibnitz's independence, and I do not myself see in what other light it can be read; the contention of the Recensio does not seem to me to touch the point in dispute. Newton afterwards believed that Leibnitz had practically appropriated his calculus; but that later belief, whether well or ill founded, is not sufficient ground for putting an interpretation on the words of the scholium which they do not naturally bear.

The new calculus attracted the attention of James Bernoulli and his brother John, and in the hands of these two and of Leibnitz himself it made good its position as a mathematical instrument of the highest value. It was not however without its critics, and the objections to the higher differentials were not satisfactorily met by the Ieibnitzian school. Leibnitz at times appeals to the principle of Archimedes, but he seems to lay most stress on the truth of the results obtained, as proof of the validity of the methods. In accuracy he falls short of Newton with his method of prime and ultimate ratios.

In 1693 the second volume of Wallis's Opera was published. Wallis there prints extracts from two letters of Newton which give 
the leading ideas of his fluxional method, and here for the first time the fluxional notation appears in print. On seeing these letters John Bernoulli concluded, as he wrote to Leibnitz, that Newton's method, as mentioned in the Principia, does not really differ from that of Leibnitz and suggests that Newton may have constructed his calculus after seeing that of Leibnitz. Leibnitz puts him right on the matter, but the letter shows that Bernoulli had put the natural interpretation on the scholium.

The first public charge against Leibnitz in reference to the calculus was made by Nicolas Fatio de Duillier in a tract Lineae brevissimi descensus investigatio, published in 1699 under the sanction of the Royal Society. Fatio asserts that Newton had discovered the calculus many years before Leibnitz; "nor will the silence of the more modest Newton or the arrogance of Leibnitz, who everywhere attributes the discovery of this calculus to himself, deceive any who have gone through those documents which I myself have turned over." Fatio probably refers to the Oldenburg letters, but where he saw them we do not know.

Leibnitz was naturally incensed at the accusation, especially as it seemed to bear the mark of the approval of the Royal Society, and he applied to Wallis to help him in the matter. (Wallis's correspondence with Leibnitz was always of the most friendly character, though he was neither nostras nor apud nos.) Wallis answered that he had seen but not read Fatio's book, and that he disapproved of the attack whether it proceeded from Fatio or any one else. The approval of the Royal Society was due to an oversight, as would be seen from the accompanying letter of Sloane, the Secretary. Leibnitz then publicly replies to Fatio's charges in the Acta, for May 1700, and in the course of his answer appeals to the Principia as proof that. Newton himself recognised his independence.

That Newton should not have known of this attack, in which the Secretary of the Royal Society had to intervene, is all but incredible; the reasons for his silence can only be guessed at. In the letters to Wallis and in the preface to the De Quadratura, published in 1704, that is on occasions both before and after Fatio's impeachment of Leibnitz when the opportunity of referring to the new calculus which was being cultivated so assiduously on the Continent presented itself, he acts as if for him that calculus did not exist. In spite of the provocation he had received by Leibnitz's 
article in the Aclu for 1689 , Tentamen de molunm coelestium causis, the tone of his letter to Leibnitz in October 1693 is extremely friendly. Whether he sympathised with Fatio in his attack or not, it is impossible definitely to say. Up till this time his conduct seenıs to me beyond reproach, and seeing that he set such great store by his method of fluxions as to secure his claims to the discovery by enshrining its leading principles in the anagrams of the Oldenburg letters as well as in the scholium of the Principia, it remains a mystery why he did not step forward after the publication of Leibnitz's reply to Fatio. The article of 1689 , referred to above, may possibly have aroused his suspicions (though the letter of 1693 is rather against that hypothesis) and he may not have felt so sure of Leibnitz's straightforwardness as to give a favourable answer to his appeal, while his known dislike of controversy would restrain him from pushing his own claims. By his silence however he put himself, I think, in an unfavourable position for bringing home to Leibnitz at any later time a charge of unwarranted borrowing.

If Leibnitz felt hurt at Newton's silence, he took a very dishonourable form of revenge by referring as he did to Newton in his review in the Acta for January 1705 of the De Quadratura; however much aggrieved he may have been, and I think he had good grounds for complaint, at Newton's silence in the affair of Fatio, he only demeaned himself by speaking as he did of Newton. The general tone of the article is favourable enough, though throughout it Leibnitz bulks more prominently than Newton, but Leibnitz was grossly unjust when he went on to say "instead of the Leibnitzian differences $\mathrm{Mr}$ Newton employs and has always employed fluxions . . . In his Principia... . he has applied them elegantly, just as also H. Fabri in his Synopsis geometrica substituted the progress of motions (motuum progressus) for the method of Cavalieri." In other words, he compares Newton with Fabri, whose work according to Mr Cantor would have been completely forgotten but for this paragraph; and worse still, there is the plain suggestion that Newton's Fluxions are later than Leibnitz's Calculus and only a variation of it.

$\mathrm{Mr}$ Cantor justly censures this comparison and suggestion as well as Leibnitz's subsequent evasions ; Leibnitz even denied having written the reviow when the stress of the priority controversy was upon him. Review and denial alike leave a stain on his memory. 
In seeking to explain, though not to justify, the review, Mr Cantor says all in Leibnitz's favour that can be said and his plea is not without weight; Leibnitz wished to make Newton speak out by making him feel how keenly a man suffers under an unjust reproach. This at any rate is the best that can be said for him, whatever weight we may attach to it.

From this review, which Newton does not seem to have heard of at the time of its appearance, sprang the bitter controversy, though the immediate occasion was given by John Keill, Professor of Astronomy at Oxford, who in an article in the Phil. Trans. Vol. XXVI. issued in 1710) inserted a sentence to the effect that Newton was the first inventor of the arithmetic of fluxions, which Leibnitz had later, with a mere change of name and notations, published in the Acta Eruditorum.

Leibnitz as Fellow of the Society received his copy of the Phil. Trans. when at Berlin in 1711, and immediately wrote to Sloane demanding that Keill should withdraw his imputations. On the 22nd March 1711, at a meeting of the Royal Society, with Newton in the chair, a part of the letter was read. Newton was at first displeased with Keill's action, but at a meeting held a fortnight later Keill directed Newton's attention to the unfair account of the De Quadratura in the Acta for 1705, and Newton thereupon explained how the matter stood, giving the time of his own earliest researches. Keill was then requested to draw up a statement on the matters in dispute. At the sitting of 12 th April Newton referred to his letters to Collins; and Keill, who was present, was again asked to investigate the matter and defend the President's rights. Finally on the 24th of May Keill's answer was read, and on the 31st Sloane was instructed to forward Keill's defence to Leibnitz.

Keill's letter is addressed to Sloane. He begins by saying that he does not wish to deny to Leibnitz anything that is justly his, and he did not mean that Leibnitz knew of Newton's name and notations for his calculus; but he undertakes to prove that Newton was the first inventor, and that in his letters to Oldenburg and through him to Leibnitz, he had given such clear indications that a man of ordinary sagacity could not fail to deduce Newton's method. The review in the Acta is alleged to be the reason for Keill's action; for if it were right for the Leipzigers to credit to Leibnitz the 
discoveries made by others, the British (Keill was Scotch!) might fairly demand back what had been taken from Newton.

I think Keill's letter is a much abler impeachment of Leibnitz than Mr Cantor admits. That Newton is the first inventor, $\mathbf{M r}$ Cantor himself allows; and it seems to me that Keill seizes with remarkable skill on the portions of the letters from which Leibnitz might profit. But what Keill refuses to see is that only a man far advanced on the way to a calculus could avail himself of Newton's communications as Leibnitz might have done; unless Leibnitz had previously discovered the fundamental features of the calculus, the information given by Newton would not have borne the fruit Keill supposed it to do.

How far Keill's ignorance of the fact that Newton's second letter was answered immediately after its receipt is to be held accountable for the firm position he takes up is difficult to decide. If this ignorance be so important as Mr Cantor thinks, then it must count for a good deal in the judgment we form as to the bitter feelings that Newton and his supporters entertained. As regards the later developments it should be noted that Newton in his letter to Conti of February 26th, 1716, expressly deduces from a remark in the first letter of Leibnitz to Conti the conclusion that Leibnitz had seen the second letter at Collins's. However improbable it is that Leibnitz then saw the letter, he gives no contradiction to Newton's assertion; though in justice to Leibnitz it should be added that he refused to discuss the details of letters till he had had time to examine his papers; and it is undoubted that his energies were so fully claimed for other work that he had little time for the thorough examination of all the allegations made against him.

The summer of 1711 was a very busy one for Leibnitz, and only on the 29th of December did he send on to Sloane his reply. He acknowledges Newton's independence, holding however by the justice of his review; he, at his age, considers Keill a hominem doctum sed novum and but little fitted to judge of earlier transactions; and he submits that the Society should put down unjust clamour, of which Newton, the one best acquainted with the facts, does not, he is persuaded, approve.

At the meeting of the Royal Society on 31st January 1712 Leibnitz's letter was read and handed over to Newton, who 
apparently declined to take action. On the 6th of March the Society, "since Leibnitz had appealed from Keill as homine novo to the Society itself," ordered that the older documents should be consulted, and appointed certain Fellows, who seemed more competent to examine them, to inquire into the matter and to report what they found in the old writings, along with their opinion." At first the Committee consisted of Arbuthnot, Hill, Halley, Jones, Machin and Burnet, but later Robartes, Bonet (the Prussian minister), De Moivre, Aston and Brook Taylor were added.

$\mathrm{Mr}$ Cantor discusses the composition of the Committee and recognises the competence of Halley, Machin, and Jones; also of De Moivre and Brook Taylor, but as they were only chosen a week before the Report was submitted, he considers their presence as merely ornamental. There is no evidence, he thinks, that the others were fit to judge in the case. * It is, by the way, only by straining the meaning of the words that the Committee can be described as composed of "gentlemen of various nations," as Newton maintained it was.

On April 24th the Report was subnitted. Its main points are:-I. Leibnitz's visits to London and correspondence with Collins; Collins's liberality in communicating what he had from Newton and Gregory. II. Leibnitz's appropriation of Mouton's differential method and the want of evidence that he had any other before his letter of 21 st June 1677, a year after the tangent letter had been sent to Paris to be communicated to him, " in which letter the method of fluxions was sufficiently described to any intelligent person." III. Evidence that Newton had invented his method before 1669. IV. The differential method is one and the same with the method of fluxions, excepting the name and mode of notation; the attribution to Leibnitz of the calculus was due to ignorance of the correspondence with Collins and Oldenburg. The Committee reckon that Newton was the first inventor, and Keill, in asserting the same, had been no ways injurious to Leibnitz; and they recommend the publication of documents. $\dagger$

- De Morgan says Burnet was a son of the Bishop and a pupil of John Craig (Phil. Mag. [4 S] IV., p. 325, Note † (1852).

$+\mathrm{Mr}$ Cantor has misunderstood the last clause of the Latin version of the Report ; it obviously means, "as also whatever else fit for elucidating this history might occur in the A.E." 
The Society accepted the recommendation and undertook the cost of publication, though it did not formally assent to the judgment of the Committee. The collection of documents, now known as the Commercium Epistolicum, was sent in name of the Society to mathematicians in various countries, and, later on, 25 copies were directed to be sent to a bookseller in Holland, to be disposed of by him for behoof of the Society. The Society apparently took no special pains to let Leibnitz have a copy without delay.

The most important documents in the book are:-The $D e$ Analysi; letters between Newton and Collins, between Collins, Gregory and other mathematicians, between Newton, Oldenburg and Leibnitz, between Wallis and Leibnitz; extracts from Fatio's Lineae brev. desc., from the review of the De Quadratura; the letters between Leibnitz and Sloane, between Keill and Sloane; and finally the Report of the Committee, in the original English and in a Latin translation where "to any intelligent person" appears as "idoneo hav um rerum cognitori." The original English is probably the rashest assertion ever made on a mathematical subject, and the Latin version is certainly needed to interpret it. Apparently the Conmittee attributed more to the intelligence of the English readers of the Report than they did to that of the foreign mathematicians.

It would be too much to expect that the Committee should not have strong leanings in favour of Newton, and had they confined themselves to showing that he was the first inventor and that Leibnitz was at the best only second, their work might have served a very useful purpose. But they took a totally different course ; they not only do their best to put Newton's claims in the strongest light, as they were possibly entitled to do, but without giving Leibnitz any chance of explanation they do their utmost to prove him the meanest thief: In making their extracts they frequently bury under a reference what tells in favour of Leibnitz while printing what seems to go against him. But the part of the book that deserves the severest censure consists of the foot-notes that occur on nearly every page; in these the animus of the Committee or of the editors is most glaringly displayed; every letter is annotated from the point of view that his plagiarism is proved, and the most innocent expressions are twisted to his disadvantage. In some cases the notes, even when they are unfavourable to 
Leibnitz, are not, I think, unjust; but to any one reading the book, the cumulative impression of the notes and comments on the work of a man who, it must be remembered, had had no chance of giving his own version, would be all but certainly one of his complete depravity.

It is difficult to make out who actually drew up the foot-notes and the connecting narrative, for the original English Report only speaks of Extracts from Letters and Papers as being presented to the Society; Halley, Jones and Machin seem to have acted as editors of the Comnercium, but the book was ordered to be delivered to each member of Committee to examine it before its publication. A note appended to the passage of Leibnitz's letter to Sloane, in which he refers to Newton, reads, "Newton and Leibnitz are neither fit judges nor witnesses. On the old documents the judgment must be based." The natural inference from this note is that the Committee had consulted Newton just as little as Leibnitz. But this inference would not be correct, for one portion at least of the connecting narrative (Cantor, p. 300) is from a manuscript of Newton, drawn up by him, in all probalility, about the beginning of 1712 and therefore not an "old document." If Newton had merely placed his old MSS. at the disposal of the Committee there would be little fault to find with the foot-note translated above, though it would be unfair not to have requested the same information from Leibnitz; but Newton's manuscript was written specially in view of the controversy, and the foot-note directly suggests what the Committee knew to be not true.

I do not wonder that Newton felt deeply insulted by the terms of Leibnitz's paper in the Acta, for in the two Oldenburg letters he had, while refraining from any exposition of his method of fluxions, been exceedingly generous in his communications; and whether Leibnitz gained much or little from them for his calculus, his later work must have convinced him that Newton had anticipated him on many points. Indeed before the Fatio incident Leibnitz had frequently stated as much. But however much I sympathise with Newton (if I may venture to use such a phrase) I cannot see that his conduct in the controversy raised by Keill is at all worthy of him ; his claims were, in my judgment, so indisputable that he might well have put the most generous construction on the work of Leibnitz and have passed by his insinuations with the contempt 
they deserved. And besides, the keenness with which he felt the insinuations of Leibnitz might have led him to see how Leibnitz must have suffered under the charges of Fatio-accusations that Leibnitz refuted by reference to Newton's own published statement, interpreted in a way that Newton did not challenge.

The controversy that followed on the publication of the Commercium Epistolicum is far from pleasant reading. Leibnitz had good grounds of complaint, and his multifarious occupations left him little time or opportunity for effective reply. He was for a considerable time absent from Hanover, and he refused to discuss details of dates and documents till he had an opportunity of examining his papers. But he only increased the suspicions attaching to him by his wild charges against Newton and by the introduction of matter wholly foreign to the dispute. The Charta volans of 1713 , with its extracts from the letter of an eminent mathematician, merely made matters worse for him, and the mediation of Chamberlayne and Conti was of no avail. Mr Cantor in referring to Newton's charge that Leibnitz had borrowed from Barrow (p. 311) does less than justice to Leibnitz's acuteness; Leibnitz answers Newton in practically the same terms as Mr Cantor does himself. (Letter to Conti of 9th April 1716.) The letters produced by the mediation contain passages in which Leibnitz, with justice, insists on the unfairness of charging one with plagiarism who has developed theories beyond the stage which the original authors reached, but there is no real approach to a settlement of the matters in dispute.

In one of his letters Leibnitz promises a Commercium Episto. licum of his own, and some time after his return to Hanover in the autumn of 1714 he took the better plan of writing the story of his invention, under the title Historia et origo calculi differentialis. Unfortunately for the good name of Leibnitz this document did not see the light till 130 years after his death. It is very favourably distinguished from his other contributions to the controversy ; there is no imputation on the good faith of Newton, but he holds firmly by his own independence.

The part No. 342 of the Philosophical Transactions (January, 1715) contained a long "Account of the Book entitled Commercium Epistolicum." The Account, according to the opening sentence, has for its object to give a fuller statement of the Commercium than is to be obtained from the mutilated and imperfect versions current 
abroad. The narrative is written from the point of view of the foot-notes, and contains one assertion that is not explicitly made in the Commercium itself, namely, that Leibnitz saw Newton's second letter on his second visit to London. Such an assertion might hare some reasonableness after Newton's letter to Conti of 26th February 1716 , but there are no grounds apparent for such a positive statement at the time when the "Account" was written. It seems as if the assertion can have been at best only a guess; and it was grossly unfair, to say the least, to introduce into what professed to be an account of the Commercium an important piece of evidence like this without express mention that it was new and with proof of its truth. The "Account" states in positive terms that the Society could only proceed, in the way of answer to Leibnitz's letter, by an examination of old documents, and could not accept either Newton or Leibnitz as a witness. But it has been pointed out above that the Committee quoted from one recent manuscript of Newton, and while their actual quotation occurs in the connecting narrative supplied by the editors and is not presented as a paper in the case, it nevertheless inevitably suggests that Newton had more to do in the preparation of the Commercium than the Committee give its readers to understand. The suggestion can only be confirmed by the knowledge, which is now certain, that the author of the Account in the Transactions of the Society was Newton himself.

In 1716 Leibnitz died without publishing his own Commercium, and in 1722 a new edition of the Commercium of 1712 was issued, with a new preface, a Latin translation of the "Account," and an Appendix containing the opinion of the eminent mathematician quoted in the Charta volans of 1713 with an Annotatio on this opinion. With the exception of these additions, the new issue is represented as a reprint of that of 1712 , retaining even the original title page before the older portions. But it is as a matter of fact not a simple reprint; there are several changes, most of them of no great importance, though unwarrantable according to modern notions, in a professed reprint; but one addition has reference to a document (the tangent letter of 1672) that has a prominent place in the Committee's Report. The Collectio of Collins which contained that letter in full is now said to have been sent to Leibnitz on 26th June 1676. Recent inquiries have made it all but certain that the Collectio was never sent but only an abridgement which 
did not contain the example by which the method of drawing tangents, as the Commercium (p. 100) says, was expounded.

The author of the new introduction and of the Annotatio was Newton. The opening sentence of the Annotatio might be made to bear the interpretation put on it by M. Lefort in his edition of the Commercium, namely, that the writer of it suggests that Keill was the author of the Recensio; it is possible to put another interpretation on it, but no interpretation is likely to make this part of the case much better for Newton. Sir David Brewster, in his Life of Newton, speaks thus:- "It is due to historical truth to state that Newton supplied all the materials for the Commercium Epistolicum and that, though Keill was its editor and the Committee of the Royal Society the authors of the Report, Newton was virtually responsible for its contents."

$\mathrm{Mr}$ Cantor remarks in his closing words on the controversy that it had no proper continuation and that till the present century the conviction of Leibnitz's plagiarism from Newton was all but universal. The publication of Leibnitz's papers has changed the attitude of the mathematical public; though whether that change is so complete as $\mathrm{Mr}$ Cantor says, is doubtful. The adherents of Newton were right in contending that Newton was first in possession of the calculus; it is equally true that it was Leibnitz who first made it accessible to mathematicians. How much Leibnitz derived from Newton can never be definitely settled; I think all the evidence shows that he was on the lines of his calculus before he came under the influence of Newton, but I do not fully agree with $\mathrm{Mr}$ Cantor in his estimate of the help he obtained from Newton. The controversy that embittered Leibnitz's last days was largely due to his own action, but the later developments of it bring Newton too before us in a line of conduct that his warmest admirers must condemn.

Mr Cantor's IIistory on which this paper has been based can be thoroughly recommended as a temperate and able account of the dispute; the other portions of his great work, with which I have no space to deal, show in an equally high degree his great merits as a historian.

On the Foundations of Dynamics.

By Dr Peddie. 